\title{
Pressure gauge accuracy and tire maintenance awareness among vehicle owners in Birnin Kebbi, Nigeria
}

\author{
Ademola James Adeyemi ${ }^{*}$, Olusegun Isa Lasisi ${ }^{1}$, Abubakar Arzika Zaki ${ }^{1}$, Sani Isa Besse ${ }^{2}$, \\ Muhammad Bello Ambursa ${ }^{3}$ \\ ${ }^{1}$ Department of Mechanical Engineering, Waziri Umaru Federal Polytechnic, Birnin Kebbi, Nigeria \\ ${ }^{2}$ Department of Technical Education, Waziri Umaru Federal Polytechnic, Birnin Kebbi, Nigeria \\ ${ }^{3}$ Department of Education, Waziri Umaru Federal Polytechnic, Birnin Kebbi, Nigeria
}

\section{ARTICLE INFORMATION}

\section{Article history:}

Received: November 27, 2020

Revised: December 20, 2020

Accepted: December 24, 2020

\section{Keywords:}

Road accident

Tire blowout

Vulcanizer

Safety awareness

\section{A B S T R A C T}

Aside from human factors, tire blowouts and other tire imperfections are major contributors to the persistently high road accident rate. While tire imperfections are categorized as part of the mechanical factors affecting road accident, the tire maintenance personnel and the vehicle owners' human behavior plays a significant role in ensuring that accidents due to tire imperfections are minimized. Therefore, this study aims to determine the accuracy of the pressure gauges used by tire maintenance personnel, popularly called vulcanizers in Nigeria, and to determine the level of awareness of vehicle owners about the basic information that affects the safe use of tires on the road. The study consists of two stages. The first stage investigates the accuracy of the pressure gauges used by twenty vulcanizers in four different districts in Birnin Kebbi, the northwestern part of Nigeria. The second stage was an online survey regarding the tire maintenance behavior of 87 participants, who were formally educated from Diploma to $\mathrm{Ph} . \mathrm{D}$. level. The study's findings showed that about $25 \%$ of the vulcanizers do not use pressure gauges to measure air pressure during tire inflation, and less than $17 \%$ of the readings taken were accurate. Yet about $60 \%$ of the respondents believe that vulcanizers' pressure gauges are reliable and less than $30 \%$ of the respondents know that the expiring date of tires is four years in Nigeria. Therefore, there is an urgent need for proper awareness about tire usage and maintenance among the general population. It would also be appropriate to include such basic road safety information in the school curriculum at all levels.

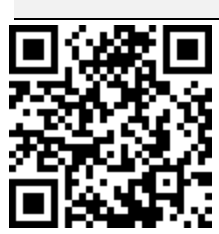

This is an open-access article under the CC-BY-NC-SA license.

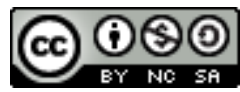




\section{INTRODUCTION}

Road accident is a major cause of death in the world. It has been recognized as a major global public health issue that has not received sufficient efforts to significantly prevent further occurrence [1], [2]. Consistently in the past decades, it ranks among the top 10 causes of mortality among humans. Apart from death, it also leads to disabilities among humans. Economically, road accidents result in loss of productivity for individuals and organizations, resulting in national productivity loss. Records show that more than $50 \%$ of those killed by road accidents are age 15-44 years, which are the active workingage of any population [1]. Hence, road accidents indirectly affect children and the elderly as it mostly takes away the breadwinners in the family. It also directly impacts the children population, as it is now the leading cause of death among 5-29year-olds [3]. This has led to the extension of one of the sustainable development goals, which aimed to reduce the number of deaths by road accidents to half, from 2020 to 2030 [4].

The 2018 global status report on road safety stated that road accidents are associated with the national standard of living [3]. According to the report, the chance of death by road accident is three times higher in low-income countries than Africa presently has the highest death rate by road accidents, and the rate has consistently. The rise in the region for decades [3]. The high rate of road accidents on the continent is regardless of the fact that Africa is the least motorized continent on the planet [5]. Most of these deaths in Africa occur among occupants of 4-wheeled vehicles (40\%), pedestrians $(40 \%)$, and motorized 2-3 wheelers (9\%).

Nigeria, the most populous and one of Africa's largest economies, has one of the highest road accidents in Africa and the world [6], [7]. Although a report of the analysis of road crashes from the previous decade (2001-2010) indicates that the government's program has successfully reduced the number of crashes and fatalities [8], the rate is still significantly high. Road accident fatalities in Nigeria is ranked $2^{\text {nd }}$ among 193 countries [9]. According to the 2019 Road Transport data of the Nigerian Bureau of Statistics, there are 11,151 road traffic crashes involving 79,301 people in the year. The figure represents a $13.7 \%$ increase when compared with the figure for 2018 . About $26 \%$ of these accidents are fatal, leading to the death of 5,483 people, and almost 36,000 people were injured. The number of deaths represents about a $6 \%$ rise when compared with the previous year. The continuous rise is a serious challenge to the Federal Road Safety Commission who had set a goal of reducing the rate of road accidents by $50 \%$ by 2020 [5]. The report also shows that gender and age are risk factors of road accidents in Nigeria, with $78 \%$ of road accident fatalities occurring among males and only $8 \%$ of the fatalities were children. Fig. 1 shows the categories of vehicles commonly involve in road accidents in Nigeria. Most of these vehicles are commercially (65\%) and privately owned (34\%), while government and diplomatic vehicles are seldomly involved in road accidents.

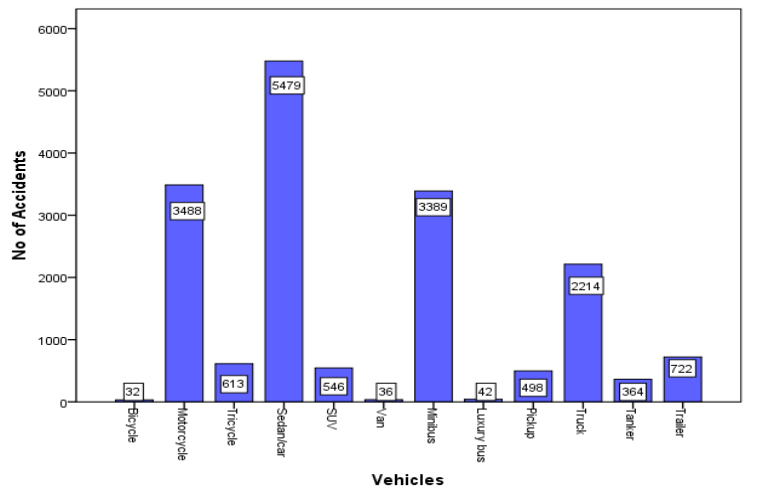

Fig. 1. The number of Accidents caused by different types of vehicles [10]

The factors contributing to these accidents can be broadly categorized as human factors, mechanical factors, and environmental factors. Human factors related to the behavior of drivers, passengers, or pedestrians. Mechanical factors relate to the failure or malfunctioning of mechanical or other vehicles' components, while environmental factors relate to the state of the roads, facilities provided and terrain, weather, etc. In Nigeria, major causes of road accidents are speed violations, wrongful overtaking, dangerous driving, and tire blowouts [10]. Other causes are drinking alcohol, answering calls, expired tire, improper sizing, or overloading. Another important factor is the increasing rate of motorization in the country. States with good roads and a higher standard of living also reported a higher rate of crashes and fatalities [8], [10].

The tire is one of the major components that affect the safety of vehicles [11]. Apart from human factors, numerous reports in the literature have identified tire imperfection, especially tire blowout, as the major contributor to road accidents 
across the globe [12], [13]. According to Michelin tire, tire blowout is responsible for about 23,000 road crashes every year, resulting in more than 500 fatalities [14]. About 7\% of the reported highway accident in Nigeria resulted from tire blowouts [10], while it was about $13 \%$ in Saudi Arabia [15]. Poor maintenance or monitoring of the tires was reported to be majorly responsible for accidents from tire imperfection in the country [16].

Two major risk factors for tire blowout is under-inflation and overloading of vehicles [17]. Another important risk factor is tire adhesion. Factors that affect the tire adhesion to the road include the tire parameters, the vehicle parameters, the road surface, and the volume of the load carried [18]. While tire blowout is mostly investigated as a mechanical factor of road accidents because it is a major component of vehicles, its effects on accident occurrence cannot be independent of human behavior. This is because pressure monitoring and adjustment are carried out by the tire maintenance personnel and vehicle drivers or owners. Hence, the aim of this study is two-fold: to investigate the accuracy of the pressure gauges used by tire maintenance personnel, and also to determine the level of awareness of vehicle owners about the basic information that affect the safe use of tires on the road.

\section{RESEARCH METHODS}

The study is cross-sectional, targeted at measuring the common behavior of two categories of people who maintain vehicle tires. These are the tire maintenance personnel and vehicle owners or drivers. The first stage of the study was conducted in Birnin Kebbi metropolis, the capital of Kebbi state in the country's Northwest region. It involved visiting some tire maintenance personnel, locally referred to as vulcanizers in Nigeria. Because of the existence of only a few auto workshops and the cost of patronizing standard tire maintenance workshops in the country, most vehicle owners and commercial operators rely on the local vulcanizers, who are primarily responsible for patching and inflating tires in the country. The vulcanizers belong to the self-regulated informal sector in the economy. It is therefore difficult to confirm the exact number of such personnel in the city. For good representation, the metropolis was stratified into four districts; the state secretariat where most civil and government activities are carried out, a commercial area, an academic area where a tertiary institution is located, and a residential area. Five vulcanizers were visited in each of the districts. A multipurpose 3.3L engine vehicle (MPV) was used for the study. Before visiting each district, the four tires of the MPV were gauged to a predefined pressure. At each center, the operator was asked if there was a pressure gauge or not. Where there was a gauge, the gauge was used to check the air pressure in each of the four tires of the car at least twice before the reading is recorded. After completing the gauging at a particular district, the tires were inspected and gauged with the standard pressure gauge to maintain the study's initial pressure. The total distance covered during this stage of the research was about $15 \mathrm{~km}$. The pressure gauge at a center was deduced to be accurate when the tire pressure measured using the gauge at the center is equal to that of the standard pressure gauge. Thereafter, the percentage accuracy of each center was calculated as

$A=\frac{\text { Number of tires measured accurately }}{4} \times 100 \%$

A gauge is also said to be under measuring or overinflating tires when the pressure measured is greater than that of the standard pressure gauge. In comparison, a gauge is said to be over measuring or underinflating tires when the pressure measured is less than that of the standard pressure gauge. The second stage of the study involved the administration of an online questionnaire to selected participants. The survey was made available from 4 June to 24 July 2020 . It consists of twenty questions on demographic information, vehicle types, and tire maintenance culture. The participants were recruited from WhatsApp groups of the academic staff of tertiary institutions. Participation was voluntary, and the aims of the study were clearly stated with the link to the online survey. Data from both stages were statistically analyzed using descriptive and correlational techniques. All the analysis were carried out using SPSS version 18.

\section{RESULTS AND DISCUSSION}

Table 1 shows the tires' measured pneumatic pressure at different tire maintenance points or vulcanizers in Birnin Kebbi Metropolis. The column for accuracy, under-measurement, and over-measurement are all percentages of the number of tires with the same readings as the standard air pressure gauge. 
Table 1. Comparison of tires pressures (psi) from the standard gauge and gauges by vulcanizers in Birnin Kebbi

\begin{tabular}{|c|c|c|c|c|c|c|c|c|}
\hline & $\begin{array}{c}\text { Gauge } \\
\text { available }\end{array}$ & $\begin{array}{l}\text { Front } \\
\text { left } \\
\text { (psi) }\end{array}$ & $\begin{array}{l}\text { Front } \\
\text { right } \\
\text { (psi) } \\
\end{array}$ & $\begin{array}{c}\text { Rear } \\
\text { left } \\
\text { (psi) }\end{array}$ & $\begin{array}{l}\text { Rear } \\
\text { right } \\
\text { (psi) }\end{array}$ & $\begin{array}{c}\text { Accuracy } \\
(\%)\end{array}$ & $\begin{array}{c}\text { Under- } \\
\text { measurement } \\
(\%)\end{array}$ & $\begin{array}{c}\text { Over } \\
\text { measurement } \\
(\%) \\
\end{array}$ \\
\hline Standard & Yes & 45 & 50 & 40 & 45 & & & \\
\hline 1 & Yes & 28 & 30 & 20 & 20 & 0 & 100 & 0 \\
\hline 2 & Yes & 35 & 20 & 25 & 35 & 0 & 100 & 0 \\
\hline 3 & Yes & 45 & 40 & 40 & 30 & 50 & 50 & 0 \\
\hline 4 & Yes & 40 & 35 & 33 & 35 & 0 & 100 & 0 \\
\hline 5 & Yes & 40 & 30 & 22 & 30 & 0 & 100 & 0 \\
\hline 6 & No & - & & & & & & \\
\hline 7 & Yes & 58 & 46 & 46 & 46 & 0 & 25 & 75 \\
\hline 8 & Yes & 42 & 30 & 30 & 30 & 0 & 100 & 0 \\
\hline 9 & Yes & 45 & 50 & 40 & 45 & 100 & 0 & 0 \\
\hline 10 & Yes & 45 & 50 & 40 & 45 & 100 & 0 & 0 \\
\hline 11 & Yes & 40 & 39 & 39 & 39 & 0 & 100 & 0 \\
\hline 12 & No & - & & & & & & \\
\hline 13 & Yes & 50 & 40 & 40 & 40 & 25 & 50 & 25 \\
\hline 14 & Yes & 39 & 32 & 30 & 30 & 0 & 100 & 0 \\
\hline 15 & No & - & & & & & & \\
\hline 16 & No & - & & & & & & \\
\hline 17 & Yes & 31 & 22 & 22 & 21 & 0 & 100 & 0 \\
\hline 18 & Yes & 43 & 40 & 40 & 40 & 25 & 75 & 0 \\
\hline 19 & Yes & 30 & 21 & 27 & 25 & 0 & 100 & 0 \\
\hline 20 & No & - & & & & & & \\
\hline
\end{tabular}

The result shows that 5 of the 20 centers, which translate to $25 \%$ of the air dispensers, did not gauge compressed air inflated into the tires. Of the 60 individual measurements carried out at the centers, only ten measurements have exact values as the standard gauge measurement, which translates to less than $17 \%$. However, when the centers are assessed based on absolute accuracy, only two centers used gauges with similar accuracy $(100 \%)$ as the standard and calibrated gauge. One of the centers was over-measuring (under-inflation), while the remaining twelve centers with gauges were under-measuring (overinflation).

Eighty-seven educated people, made up of 74 males and 13 females, completed the online survey. About $75 \%$ of them are aged between 30 and 49 years, and about half of the participants have a Masters degree, another $40 \%$ had a Bachelors's degree, and six people had a Ph.D. Only one of the participants had a National Diploma/National Certificate of Education, the minimum qualification for teaching. About $92 \%$ of the participants are the vehicle owners they drive, while others drive their relatives' vehicles. Table 2 shows the participants' awareness of the vehicle tires' basic information and the pressure measuring instruments commonly available. While most of the participants are aware of the sizes and recommended, tire pressure for the vehicles, very few can independently monitor the tire pressure. Table 2 also reveals that only seven of the participants reported that their vehicles had a Tire Pressure Monitoring System (TPMS).

Table 2. Participants vehicle tire information and availability of pressure monitoring devices

\begin{tabular}{|c|c|c|c|}
\hline & Yes & No & Maybe \\
\hline $\begin{array}{l}\text { I know the size of my } \\
\text { vehicle's tire }\end{array}$ & 70 & 13 & 4 \\
\hline $\begin{array}{l}\text { I know the recommended } \\
\text { pressure for my vehicle's } \\
\text { tire }\end{array}$ & 58 & 20 & 9 \\
\hline $\begin{array}{l}\text { I have a personal tire } \\
\text { pressure gauge }\end{array}$ & 10 & 75 & (2) \\
\hline My vehicle has a TPMS & 7 & 43 & $6(21)$ \\
\hline
\end{tabular}


In terms of the type of tires purchased, only $48 \%$ of the respondents purchase new tires, while about $20 \%$ prefer imported fairly used tires. The remaining participants buy tires based on the available funds, which implies that they buy new tires when there are sufficient funds but will settle for fairly used otherwise. However, the proportion of the participants who use new tires in this study is higher than what is recorded in other studies because the sample population in this study is among the government's highest-paid [16]. About $38 \%$ of the participants only change their tires when there are signs of worn-out (no threading visible), and another $17 \%$ changed it when it is defective. $25.6 \%$ changed it every two years while almost $15 \%$ changed it every $3-4$ years.

When asking how frequent do they gauge their tires, about $67 \%$ of the participants gauge their tires whenever they observed that the tires are low in pressure, $9 \%$ gauge the tires weekly, while $9 \%$ and $8 \%$ gauge it monthly or whenever there is a need to embark on a journey respectively. Most of the participants $(87 \%)$ claimed to only visit centers with functional pressure gauge, while the others did not bother or trust the vulcanizers' judgment. Fig. 2 shows that almost $60 \%$ believe that most of the centers have a functional pressure gauge while about $21 \%$ do not believe that the gauges are reliable. Table 3 reports on participants' understanding of basic tire maintenance and usage information.

Table 3. Participants opinion about tire usage practices

\begin{tabular}{lccc}
\hline & Yes & No & Maybe \\
\hline $\begin{array}{l}\text { It is okay to buy fairly- } \\
\text { used tires }\end{array}$ & 44 & $27(11)$ \\
It is okay when the tire & & & \\
pressure is above the & 1 & 77 & $7(2)$ \\
recommended pressure & & & \\
$\begin{array}{l}\text { It is okay when the tire } \\
\text { pressure is below the }\end{array}$ & 69 & $7(2)$ \\
recommended pressure \\
$\begin{array}{l}\text { It is okay to change the } \\
\text { tire rims in order to buy } \\
\text { affordable tires }\end{array}$ \\
$\begin{array}{l}\text { *The numbers in the brackets represent the number of } \\
\text { participants that left the questions unanswered }\end{array}$
\end{tabular}

Most participants know it is not appropriate to drive vehicles with tires that are either underinflated or over-inflated. Neither do they believe that it is appropriate to drive a vehicle with foreign used tires nor to change the default rim size to another size so that they can buy and use more affordable tires. Fig. 3 also shows that most of the participants were not aware of the approved 4years expiring date for tires in the country.

The Spearman correlation analysis shows a relationship between how the people perceived the centers and where they visit to inflate their tires $(r=0.434, p=0.0001)$. Also, the number of years when people change their tires and the tire expiring date's knowledge is significantly correlated $(\mathrm{r}=0.356, \mathrm{p}=0.001)$.

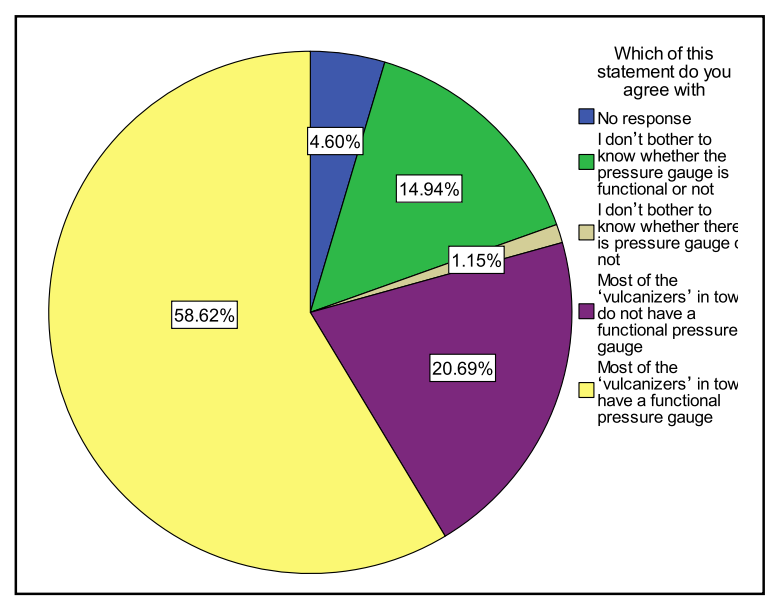

Fig. 2. Responses about the reliability of tire maintenance personnel

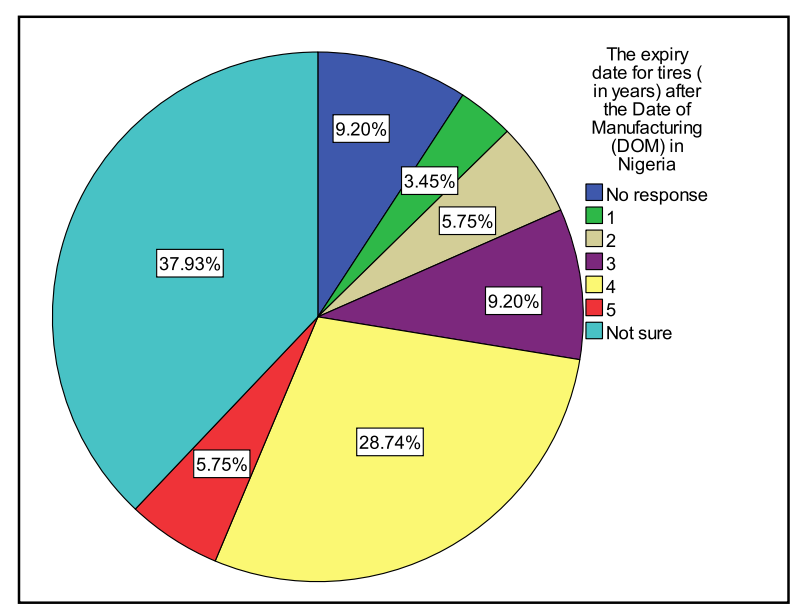

Fig. 3. level of awareness about expiring date of tires

Tire blowout and other imperfection are major causes of road accidents [13]. This risk factor and other factors responsible for road accidents have not received sufficient attention in Nigeria [2]. Although the government has been making tremendous efforts to formulate policies and develop infrastructure to regulate speed and 
driving habits on the road, individual behaviors that affect safety, such as safe and properly inflated tires, need to be given more attention. This is because vehicle owners' behavioral change can have a more positive and lasting impact than focusing on law enforcement. Most vehicle drivers and owners in Nigeria don't check the tire pressure unless it has significantly affect vehicle performance or when deflation is visually obvious. This behavior was also observed among Taiwanese drivers, although it is not reliable for identifying underinflated tires [12]. Accidents due to tire blowouts or failure are common and underreported in the country [16]. Apart from causing accidents, inappropriate tire pressure affects fuel consumption, and the increase in fuel consumption can become significant when driving within cities and towns [11], [18]. This is because the pressure in the tire has a significant effect on the tire adhesion to the road surface, thereby affecting the vehicle's safety on the road. When tire pressure is increased, the tire adhesion coefficient will decrease, leading to a reduction in the contact area between the tire and the road surface [17]. Underinflation of the tire causes an increase in tire adhesion and surface area contact between the tire and the road. Hence, It can damage the tire and causes unexpected blowout [12], [18]. It also affects the tires' lifespan as a result of the wearing out of thread pattern [11], [17].

Among the various options of inflating vehicle tires, visiting and relying on vulcanizers is the primary methods employ by Nigerians. Despite the availability of some petrol or gas fuelling stations with free pneumatic compressors for inflation and gauging of tires, this is despite the availability of some petrol or gas fueling stations. However, less than $20 \%$ of the vulcanizers pressure gauges were found to have a high degree of accuracy. This raises serious concern because almost $60 \%$ of the participants believe that the vulcanizers gauges are functional. Only about $20 \%$ of the survey respondents have the right perspective about the vulcanizers pressure gauges. This false sense of trust has a serious effect on the rate of accidents because many vehicle owners or drivers may not be aware that the vehicle tire is wrongly inflated.

Moreover, many of the vulcanizers may also not be aware of the effect of uncalibrated pressure gauges on road accidents because they are mostly uneducated or have basic primary education. Hence, without proper awareness and education, many of the vulcanizers may not know the importance of recalibration of their pressure gauges and how wrong pressure can affect the vehicles' safety. The survey result also revealed that the level of tire maintenance is poor even among society's educated members. Less than $12 \%$ of the population has a personal pressure gauge, and less than $10 \%$ claimed to use vehicles equipped with a Tire Pressure Monitoring System (TPMS). This is contrary to what is expected since most modern vehicles are installed with TPMS [19]. The analysis of the survey question on the brand of vehicle used by the participants shows that it is possible that many among the participants may not know of the availability of TPMS in their vehicles, or the TPMS may be faulty without being repaired. This may also result from their failure to know the importance of such a device in their vehicle. An oral interview with some individuals revealed that they either didn't have the vehicle manual, since a significant percentage of Nigerians buy used foreign vehicles or those with manuals don't bother to read them. Yet, knowing the importance of ensuring that TPMS is functional is vital as they serve as driving assistance to vehicle owners [20].

In this study, awareness about basic tire usage information is important because it affects people's behavior. A good illustration is a significant relationship between when people changed their tires and when they believe is the expiring date of tires. The percentage of participants $(28.7 \%)$ who know the expiring date in this study is not significantly different from the $26.6 \%$ reported in another study in the country [16]. The participants also acknowledged the dangers inherent in using foreign used tires or changing the size of the rim to reduce the cost of tires. Although most of the participants acknowledged that it is not appropriate to inflate tires above or below the recommended pressure, their perception that most gauges used at the centers are functional is dangerous since they do not have the means of validating the measurement from the centers. This inaction or risky behavior of Nigerian road users to road safety issues has also been reported in the literature [5].

Road accident has a serious economic consequence on any nation [6]. As the Nigerian government reviews current policies that affect the economy and safety on the roads, it is important to implement policy and carry out awareness that will guarantee safety on the road. This is because 
economic growth will facilitate road movement for more population, translating to an increased risk of accidents and fatalities. As revealed in Fig. 4 an independent analysis of the data from the National Bureau of Statistics and Central Bank of Nigeria reveals a significant correlation between the number of fatalities and accidents $(\mathrm{r}=0.882$, $\mathrm{p}=0.009)$ ), and also with the annual GDP growth rate $(r=0.862, p=0.013)$. This has earlier been observed by Jegede [21], and it relates to the finding by Venkatraman et al. [8] that the highest rate of crashes and fatalities in Nigeria occurs at Abuja, the national capital city, which has the best road network and is home to high-income earners. Therefore, the issue is important with the recent projection that Nigeria may be the second-most populous country by the $22^{\text {nd }}$ century [22].

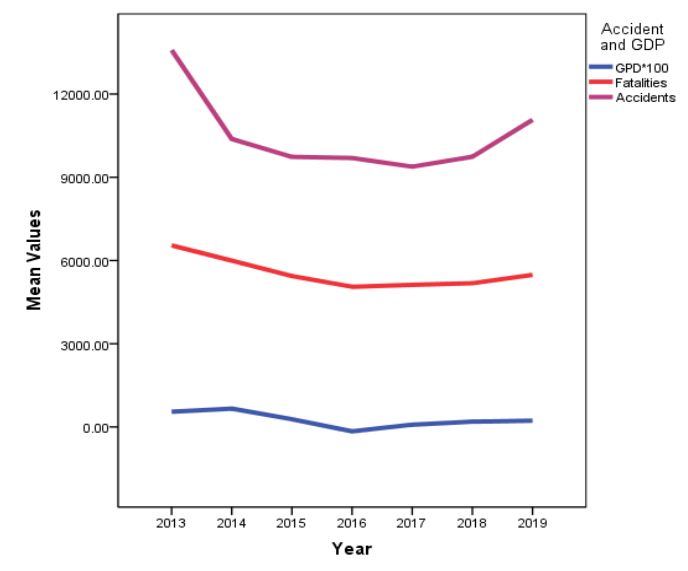

Fig. 4. The relationship between accident occurrence, fatalities, and GDP

This study also reveals that the country's economic situation can also affect the type of tires participants purchase. While the importation of used tires is not allowed, the high cost of new tires leaves many vehicle owners to purchase fairly used tires, which are mostly cheaper than new quality tires. The percentage of participants that purchase used tires is alarming because there is the likelihood that those who claimed to make purchases based on the availability of funds will also purchase used tires.

The significant correlations among variables that measure the degree of knowledge and those that demonstrated the pattern of behavior in the survey are evidence that sufficient awareness will significantly affect people's behavior. The correlations include the relationship between how the people perceived the centers and where they visit to inflate their tires and when people change their tires and the knowledge of the tire expiring date. Hence, the information about the expiring date of tires should be given serious attention too.

It is important to highlight some of the limitations of this study. Limiting the sample population to the academic staff of tertiary institutions did not allow comparison to be made among the societies' various economic sectors. The effect of other levels of education could also not be investigated because of the sampling plan. Hence, a more robust comparison with studies from other countries could not be made.

\section{CONCLUSION}

The study investigated the commitment of the two primary actors responsible for the maintenance of vehicle tires. These are the tire maintenance personnel or vulcanizers and the vehicle owners or drivers. The study shows that both parties are deficient in their responsibilities towards ensuring that only safe vehicle tires are used on the roads.

The study reveals that a significant number of vulcanizers or tire maintenance personnel use unreliable pressure gauges that lead to the underinflating and overinflating of tires. This could have a serious effect on road accidents as most vehicle owners and drivers rely on the vulcanizers for appropriate inflation of their vehicles' tires. Also, the study reveals a low level of tire maintenance awareness among participants who are lecturers in tertiary institutions. This is a reflection of the poor degree of awareness on tire maintenance in the country. Since most of the road accidents in Nigeria involve commercial and private vehicles, proper sensitization and awareness of the populace will reduce the rate of road accidents due to tire blowouts. Moreover, the inclusion of road safety in the curriculum at all levels of education will also increase the level of awareness. The level of awareness and increase in the population's knowledge base will also be necessary for the country to benefit immensely from the ongoing application of Industry 4.0 to enhance vehicle safety in the automobile industry.

\section{REFERENCES}

[1] O. mondiale de la santé et al., World Report on Road Traffic Injury Prevention. World Health Organization, 2004. Available: https://books.google.co.id/books?id=TFw ODgAAQBAJ. 
[2] E. Bun, "Road traffic accidents in Nigeria: a publichealth problem," Afrimedic J., vol. 3, no. 2, pp. 34-35, 2012. Available: https://www.ajol.info/index.php/afrij/artic le/view/86571.

[3] World Health Organisation, "Global Status Report on Road Safety 2018," 2018. Available:

https://apps.who.int/iris/bitstream/handle/ 10665/277370/WHO-NMH-NVI-18.20eng.pdf.

[4] World Health Organisation, "Road traffic injuries." $2020 . \quad$ Available: https://www.who.int/health-topics/roadsafety\#tab=tab_1.

[5] C. Uzondu, S. Jamson, and F. Lai, "Investigating unsafe behaviours in traffic conflict situations: An observational study in Nigeria," $J$. Traffic Transp. Eng. (English Ed., vol. 6, no. 5, pp. 482-492, Oct. 2019, doi: 10.1016/j.jtte.2018.06.002.

[6] A. O. Atubi, "A monthly analysis of road traffic accident in selected local government areas of Lagos State, Nigeria," Mediterr. J. Soc. Sci., vol. 3, no. 11, pp. 47-62, 2012, doi: 10.5901/mjss.2012.v3n11p47.

[7] S. E. Asogwa, "Road traffic accidents in Nigeria: A review and a reappraisal," Accid. Anal. Prev., vol. 24, no. 2, pp. 149 155, Apr. 1992, doi: 10.1016/00014575(92)90031-D.

[8] C. Venkatraman, O. Olowu, D. Turkmani, L. Hynan, and F. E. Nwariaku, "Decreasing Trends in Road Traffic Injury Incidence and Mortality in Nigeria: A TenYear Analysis," J. Surg. Res., vol. 249, pp. 163-167, May 2020, doi: 10.1016/j.jss.2019.11.033.

[9] V. N. Ukoji, "Trends and patterns of fatal road accidents in Nigeria," Violence in Nigeria: A qualitative and quantitative analysis. African Studies Centre, Leiden, pp. 13-40, 2016. Available: http://www.ifra-

nigeria.org/publications/e-papers/69-

ukoji-vitus-n-2014-trends-and-patternsof-fatal-road-accidents-in-nigeria-20062014.

[10] National Bureau of Statistics, "Road Transport Data 2019," 2020. Available: https://www.nigerianstat.gov.ng/pdfuploa ds/Road_Transport_Data\%20-
\%20Full\%20Year\%202019.pdf.

[11] O. A. Egaji, S. Chakhar, and D. Brown, "An innovative decision rule approach to tyre pressure monitoring," Expert Syst. Appl., vol. 124, pp. 252-270, 2019, doi: 10.1016/j.eswa.2019.01.051.

[12] K. Chen and C. Yeh, "Preventing Tire Blowout Accidents: A Perspective on Factors Affecting Drivers ' Intention to Adopt Tire Pressure Monitoring System," Safety, vol. 4, no. 16, pp. 1-14, 2018, doi: 10.3390/safety4020016.

[13] S. Lu et al., "Active rectifying control of vehicle with tire blowout based on adaptive fuzzy proportional-integralderivative control," Adv. Mech. Eng., vol. 11, no. 3, pp. 1-13, 2019, doi: 10.1177/1687814019835108.

[14] C. Daly, "Avoiding tire-related vehicle crashes," Fire Eng., vol. 160, no. 2, pp. 110, $2007 . \quad$ Available: https://www.fireengineering.com/wpcontent/uploads/content/dam/fe/onlinearticles/documents/FEU/FEU_2_09.pdf.

[15] N. T. Ratrout, "Tire condition and drivers ' practice in maintaining tires in Saudi Arabia," Accid. Anal. Prev., vol. 37, pp. 201-206, 2005, doi: 10.1016/j.aap.2003.03.001.

[16] R. P. Chukwugozi, "An Analysis of Vehicle Tyres Usage and Failures on the Highways : Towards Safe Driving in Ondo , Nigeria," Civ. Environ. Res., vol. 8, no. 10, pp. 1-6, 2016. Available: https://iiste.org/Journals/index.php/CER/a rticle/view/33332.

[17] M. A. Hassan, M. A. A. Abdelkareem, M. . Moheyeldein, A. Elagouz, and G. Tan, "Advanced study of tire characteristics and their influence on vehicle lateral stability and untripped rollover threshold," Alexandria Eng. J., vol. 59, no. 3, pp. 1613-1628, Jun. 2020, doi: 10.1016/j.aej.2020.04.008.

[18] B. Szczucka-Lasota, J. Kaminska, and I. Krzyzewska, "Influence of tire pressure on fuel consumption in trucks with installed tire pressure monitoring system," $J$. Silesian Univ. Technol. Ser. Transp., vol. 103, pp. 167-181, 2019. Available: http://sjsutst.polsl.pl/archives/2019/vol10 3/167_SJSUTST103_2019_SzczuckaLaso ta_Kaminska_Krzyzewska.pdf. 
[19] A. Silva, J. R. Sánchez, G. E. Granados, J. C. Tudon-Martinez, and J. de J. LozoyaSantos, "Comparative Analysis in Indirect Tire Pressure Monitoring Systems in Vehicles," IFAC-PapersOnLine, vol. 52, no. 5, pp. 54-59, 2019, doi: 10.1016/j.ifacol.2019.09.009.

[20] F. Wang, H. Chen, L. Guo, and Y. Hu, "Predictive safety control for road vehicles after a tire blowout," Sci. China Inf. Sci., vol. 61 , no. 7 , p. 70209 , Jul. 2018, doi: 10.1007/s11432-017-9330-6.
[21] F. . Jegede, "Spatio-temporal analysis of road traffic accidents in Oyo State, Nigeria," Accid. Anal. Prev., vol. 20, no. 3, pp. 227-243, Jun. 1988, doi: 10.1016/0001-4575(88)90007-3.

[22] S. E. Vollset et al., "Fertility, mortality, migration, and population scenarios for 195 countries and territories from 2017 to 2100: a forecasting analysis for the Global Burden of Disease Study," Lancet, vol. 396, no. 10258, pp. 1285-1306, Oct. 2020, doi: 10.1016/S0140-6736(20)30677-2. 